\title{
Changes in the incidence of cardiopulmonary resuscitation before and after implementation of the Life-Sustaining Treatment Decisions Act
}

\author{
Hyunjae Im¹, Hyun Woo Choe ${ }^{2}$, Seung-Young $\mathrm{Oh}^{1}$, Ho Geol Ryu ${ }^{1,2}$, Hannah Lee ${ }^{2}$ \\ Departments of ${ }^{1}$ Critical Care Medicine and ${ }^{2}$ Anesthesiology and Pain Medicine, Seoul National University Hospital, Seoul National University College of Medicine, \\ Seoul, Korea
}

Background: The Life-Sustaining Treatment (LST) Decisions Act allows withholding and withdrawal of LST, including cardiopulmonary resuscitation (CPR). In the present study, the incidence of CPR before and after implementation of the Act was compared.

Methods: This was a retrospective review involving hospitalized patients who underwent CPR at a single center between February 2016 and January 2020 (pre-implementation period, February 2016 to January 2018; post-implementation period, February 2018 to January 2020). The primary outcome was monthly incidence of CPR per 1,000 admissions. The secondary outcomes were duration of CPR, return of spontaneous circulation (ROSC) rate, 24-hour survival rate, and survival-to-discharge rate. The study outcomes were compared before and after implementation of the Act.

Results: A total of 867 patients who underwent CPR was included in the analysis. The incidence of CPR per 1,000 admissions showed no significant difference before and after implementation of the Act $(3.02 \pm 0.68$ vs. $2.81 \pm 0.75, P=0.255)$. The ROSC rate $(67.20 \pm 0.11$ vs. $70.99 \pm 0.12, P=0.008)$ and survival to discharge rate $(20.24 \pm 0.09$ vs. $22.40 \pm 0.12, P=0.029)$ were higher after implementation of the Act than before implementation.

Conclusions: The incidence of CPR did not significantly change for 2 years after implementation of the Act. Further studies are needed to assess the changes in trends in the decisions of CPR and other LSTs in real-world practice.

Key Words: advance directives; cardiopulmonary resuscitation; withholding treatment

\section{INTRODUCTION}

Withholding and withdrawal of life-sustaining treatment (LST) have been focal points in ethical debates on emerging concerns associated with dignified death of humans and end-of-life (EOL) care [1,2]. Prolonging life by LST is not always beneficial, and LST can extend hospital time for patients and family members, without a probability of recovery.

Cardiopulmonary resuscitation (CPR), including cardiac massage, which is a main component of LST, can cause severe mechanical injuries such as rib fractures, hemothorax, and

\section{Original Article}

Received: August 16, 2021

Revised: October 28, 2021

Accepted: November 13, 2021

Corresponding author

Hannah Lee

Department of Anesthesiology and Pain Medicine, Seoul National University Hospital, Seoul National University College of Medicine, 103 Daehak-ro, Jongno-gu, Seoul 03080, Korea

Tel: +82-2-2072-2065

Fax: +82-2-747-8363

E-mail: closerthan@gmail.com
Copyright (C) 2022 The Korean Society of Critical Care Medicine

This is an Open Access article distributed under the terms of Creative Attributions Non-Commercial License (https:// creativecommons.org/li-censes/by-nc/4.0/ which permits unrestricted noncommercial use, distribution, and reproduction in any medium, provided the original work is properly cited. 
other internal organ injury to the patient $[3,4]$. In a previous study, post-traumatic stress disorder symptoms were reported in family members who had witnessed unsuccessful CPR attempts on their loved ones [5]. The Act on Hospice and Palliative Care and Decisions on LST for Patients at the EOL were enforced in South Korea in February 2018 and allowed physicians and patients to establish default orders concerning EOL care, including CPR. In two retrospective studies, implementation of the LST Decisions Act showed the effect of increased self-determination rates and early decision-making for LST $[6,7]$. In addition, in a systematic review, do-not-resuscitate (DNR) orders were reportedly associated with decreased CPR [8]. However, to the best of our knowledge, the effects of the LST Decisions Act and advance care planning on the overall incidence of CPR have not been investigated.

We hypothesized that implementation of the LST Decisions Act and subsequent establishment of proactive preparation for physician orders for LST (POLST) reduces unnecessary CPR in accordance with the purpose of the Act on Hospice and Palliative Care and Decisions on LST for patients at the EOL. In addition, other CPR-related outcomes were compared assuming the patients at the EOL who underwent CPR would be affected by prior preparation for POLST.

\section{MATERIALS AND METHODS}

\section{Study Design and Patients}

This was a single-center, retrospective, observational study. Adult patients ( $>18$ years of age) who underwent CPR during the study period (February 2016 to January 2020) were included. The Act on Hospice and Palliative Care and Decisions on LST for patients at the EOL was enforced on February 4, 2018, in South Korea, and data were compared between the 2 years before implementation of the Act (pre-implementation period: February 2016 to January 2018) and the 2 years after implementation of the Act (post-implementation period: February 2018 to January 2020).

The study protocol was approved by the Institutional Review Board of Seoul National University Hospital (IRB No. H-1802-111-924). The requirement for informed consent was waived by the institutional review board due to the retrospective study design.

\section{Data Collection}

Baseline characteristics

Electronic medical records were reviewed and data regarding

\section{KEY MESSAGES}

- Implementation of life-sustaining treatment (LST) decisions did not affect the incidence of cardiopulmonary resuscitation in hospitalized patients at 2 years after enforcement of the Act.

- Cardiac arrests that occurred in terminally ill patients who had a written document regarding withholding and withdrawal of LST comprised a small proportion of the total cardiac arrests in our center, and the proportions before and after implementation of the Act were the same.

- Proactive preparation of documentation regarding withholding and withdrawal of LST with universalization of the Act will be needed to avoid unnecessary resuscitation at end-of-life stages.

baseline characteristics such as age, sex, and pre-existing comorbidities included in the Charlson Comorbidity Index were extracted as well as the case-mix indices (CMIs). The CMI is the relative value assigned to the diagnostic group of patients in the medical environment used for allocating resources to the care and treatment of patients in the group and represents the diversity or complexity of the hospital [9]. The CMI data for each period were collected to verify that patients from the two periods could be compared. The monthly total number of hospital admissions also was collected to calculate the incidence of CPR per 1,000 admissions.

\section{Data associated with CPR}

Only CPR for hospitalized patients in wards or intensive care units (ICUs) was included based on documentation of LST before the cardiac arrest. In addition, only the first recorded cardiac arrest for each patient was included in the analysis. The causes of cardiac arrest were classified according to the 5 Hs and 5 Ts (hypoxia, hypovolemia, hydrogen ions, hyperkalemia/ hypokalemia, hypothermia; tension pneumothorax, tamponade-cardiac, toxins, thrombosis-coronary, thrombosis- pulmonary) [10], and multiple selections were possible. Duration of CPR, return of spontaneous circulation (ROSC), 24-hour survival rate, and survival-to-discharge rate were recorded for each CPR performed. ROSC was defined as return of any palpable pulse in the absence of ongoing chest compressions for at least 20 consecutive minutes [11].

\section{Definitions}

CPR due to delayed documentation was defined as that per- 
formed because the DNR or POLST documentation was not completed before the initial cardiac arrest despite discussion of LST for terminally ill patients. Preventable CPR was defined as CPR that could be detected several hours before the adverse event using pre-alarm signs and that was avoidable through appropriate and prompt medical management. The time and date of CPR events were monitored to determine any pre-existing pre-alarm signs that existed within 48 hours of events and whether the events were potentially avoidable. The pre-alarm signs were abnormal vital signs based on the rapid response system trigger criteria (Supplementary Table 1).

\section{Documentation for withholding or withdrawal of LST}

The monthly numbers of DNR and POLST documentations during the study period were recorded. Additional information regarding DNR and POLST included the timing of writing the documents (before or after cardiac arrest) and whether the documents were written in the ICU or general ward. Data on the detailed form of written POLST were also collected regarding of whether POLST was completed according to the patient's own will or that of surrogates (Supplementary Table 2).

\section{Study Outcomes}

The primary outcome was the incidence of CPR per 1,000 admissions before and after implementation of the Act on Hospice and Palliative Care and Decisions on LST for patients at the EOL. The secondary outcomes were duration of CPR, ROSC rate, 24-hour survival rate, and survival-to-discharge rate. Subgroup analysis was conducted based on the location of CPR for each study outcome.

\section{Statistical Analysis}

Categorical variables were expressed as frequencies with percentages, and continuous variables were expressed as means with standard deviations. Normally distributed quantitative variables were compared using Student t-test, and non-normally distributed quantitative variables were compared using the Mann-Whitney U-test. Qualitative variables were compared using the chi-square test.

The interrupted time series was subjected to segmented regression analysis [12] to identify the correlation between enforcement of the Act and incidence of CPR per 1,000 admissions, CPR duration, ROSC rate, 24-hour survival rate, and survival-to-discharge rate. The time after the intervention variable was considered in the model to determine the time, intervention, and trend after intervention. The Durbin-Watson test [13] was performed to determine whether autocorrelation existed. The Pearson correlation coefficient was calculated to measure the statistical relationship between the monthly numbers of POLST documentation for all hospitalized patients and the incidence of CPR per 1,000 admissions.

\section{RESULTS}

From February 2016 to January 2020, a total of 867 patients who underwent CPR was included in the analysis: 446 and 421 patients in the pre-implementation and post-implementation periods, respectively (Table 1). Significant difference was not observed in the baseline characteristics including Charlson Comorbidity Index scores between the two periods, except for the prevalence of comorbidities. For all hospitalized patients in the two periods, the CMI was comparable $(1.09 \pm 0.05$ vs. $1.05 \pm 0.05, \mathrm{P}=0.515$ ) and overall hospital mortality was not significantly different between the two periods (2.3\% vs. $2.3 \%$, $\mathrm{P}=0.762)$.

\section{Characteristics of CPR between the Two Periods}

The descriptive clinical data and causes of CPR are summarized in Table 2. The location and time of CPR were similar in the two periods. Significant difference was not observed in the number of CPRs due to delayed DNR or POLST documentation $(7.0 \%$ vs. $6.4 \%, \mathrm{P}=0.752)$. Unpreventable CPRs accounted for more than $80 \%$ in both periods, and the proportion of preventable CPRs did not differ significantly before and after implementation of the Act. Acidosis and hypoxia were the two most common causes of CPR based on the 5 Hs and 5 Ts, and significant differences were not observed between the two periods for any cause of CPR.

\section{Outcomes}

The incidence of CPR per 1,000 admissions during the post-implementation period was not significantly different than during the pre-implementation period $(\mathrm{P}=0.255)$ (Table 3$)$. The ROSC rate $(70.99 \% \pm 0.12 \%$ vs. $67.20 \% \pm 0.11 \%$, $\mathrm{P}=0.008)$ and survival-to-discharge rate $(22.40 \% \pm 0.12 \%$ vs. $20.24 \% \pm 0.09 \%, P=0.029)$ increased significantly after implementation of the Act; however, CPR duration (21.16 $\pm 5.19 \mathrm{~min}-$ utes vs. $20.62 \pm 5.81$ minutes, $\mathrm{P}=0.755$ ) and 24-hour survival rate $(47.05 \% \pm 0.13 \%$ vs. $47.54 \% \pm 0.12 \%, \mathrm{P}=0.075)$ were not significantly different. In the subgroup analysis based on CPR location, the variables did not differ significantly between the two periods, except for the survival-to-discharge rate in the general 
Table 1. Baseline characteristics of CPR patients

\begin{tabular}{|c|c|c|c|}
\hline Variable & Pre-implementation $(n=446)$ & Post-implementation $(n=421)$ & P-value \\
\hline Age (yr) & $65.95 \pm 14.15$ & $66.47 \pm 13.58$ & 0.580 \\
\hline$<50$ & 55 (12.3) & $44(10.5)$ & \\
\hline $50-59$ & $72(16.1)$ & $61(14.5)$ & \\
\hline $60-69$ & $119(26.7)$ & $125(29.7)$ & \\
\hline $70-79$ & $130(29.2)$ & $130(30.9)$ & \\
\hline$\geq 80$ & 70 (15.7) & $61(14.5)$ & \\
\hline Male & $266(59.6)$ & $259(61.5)$ & 0.572 \\
\hline Charlson comorbidity index score & $5.80 \pm 2.65$ & $5.68 \pm 2.88$ & 0.519 \\
\hline \multicolumn{4}{|l|}{ Comorbidity $^{a}$} \\
\hline Myocardial infarction & $44(9.9)$ & $64(15.2)$ & 0.017 \\
\hline Congestive heart disease & $51(11.4)$ & $48(11.4)$ & 0.988 \\
\hline Peripheral vascular disease & $15(3.4)$ & $24(5.7)$ & 0.097 \\
\hline Cerebral vascular disease & $60(13.5)$ & $43(10.2)$ & 0.141 \\
\hline Dementia & $15(3.4)$ & $21(5.0)$ & 0.231 \\
\hline Chronic obstructive pulmonary disease & $19(4.3)$ & $7(1.7)$ & 0.025 \\
\hline Rheumatic disease & $19(4.3)$ & $16(3.8)$ & 0.731 \\
\hline Peptic ulcer disease & $26(5.8)$ & $1(0.2)$ & $<0.001$ \\
\hline \multicolumn{4}{|l|}{ Liver disease } \\
\hline Mild & $46(10.3)$ & $7(1.7)$ & $<0.001$ \\
\hline Moderate to severe & $64(14.4)$ & $34(8.1)$ & 0.004 \\
\hline \multicolumn{4}{|l|}{ Diabetes mellitus } \\
\hline Uncomplicated & $103(23.1)$ & $74(17.6)$ & 0.044 \\
\hline Complicated & $50(11.2)$ & $44(10.5)$ & 0.719 \\
\hline Hemiplegia & $5(1.1)$ & $3(0.7)$ & 0.530 \\
\hline \multicolumn{4}{|l|}{ Chronic kidney disease } \\
\hline Moderate to severe & $97(21.8)$ & $92(21.9)$ & 0.970 \\
\hline \multicolumn{4}{|l|}{ Solid tumor } \\
\hline Localized & $116(26.0)$ & $59(14.0)$ & $<0.001$ \\
\hline Metastatic & 65 (14.6) & 88 (20.9) & 0.015 \\
\hline Leukemia & $23(5.2)$ & $34(8.1)$ & 0.083 \\
\hline Lymphoma & $20(4.5)$ & $21(5.0)$ & 0.727 \\
\hline Acquired immune deficiency syndrome & $1(0.2)$ & $1(0.2)$ & 0.967 \\
\hline Medical or surgical patients & & & 0.307 \\
\hline Medical & $358(80.3)$ & $326(77.4)$ & \\
\hline Surgical & $88(19.7)$ & $95(22.6)$ & \\
\hline
\end{tabular}

Values are presented as mean \pm standard deviation or number (\%). Pre-implementation: February 2016 to January 2018, Post-implementation: February 2018 to January 2020.

CPR: cardiopulmonary resuscitation.

${ }^{a}$ Comorbidities used to calculate the Charlson comorbidity index.

ward subgroup. The survival-to-discharge rate of CPR in the ward significantly increased after implementation of the Act. In addition, significant statistical correlation was not observed between the monthly number of written DNR or POLST in all hospitalized patients and the incidence of CPR per 1,000 admissions (Figure 1).

\section{Characteristics of DNR and POLST between the Two Periods}

The number of DNR documentations for patients with CPR decreased after implementation of the LST Act (Table 4). Most DNR documentations in the two periods were completed after the initial cardiac arrest. Among the 421 patients undergoing CPR in the post-implementation period, $22.6 \%$ completed 
Table 2. Descriptive clinical data and causes of CPR

\begin{tabular}{|c|c|c|c|}
\hline Variable & Pre-implementation $(n=446)$ & Post-implementation $(n=421)$ & P-value \\
\hline Location of CPR & & & 0.496 \\
\hline ICU & $227(50.9)$ & $224(53.2)$ & \\
\hline Time of CPR & & & 0.788 \\
\hline Morning (06:00-12:00) & $113(25.3)$ & $117(27.8)$ & \\
\hline Afternoon (12:00-18:00) & $120(26.9)$ & $103(24.5)$ & \\
\hline Night (24:00-06:00) & $99(22.2)$ & $91(21.6)$ & \\
\hline CPR due to delayed documentation ${ }^{a}$ & $31(7.0)$ & $27(6.4)$ & 0.752 \\
\hline Preventable/unpreventable CPR & & & 0.462 \\
\hline Preventable CPR & $76(17.0)$ & $64(15.2)$ & \\
\hline Unpreventable CPR & $370(83.0)$ & $357(84.8)$ & \\
\hline Acidosis & $151(33.9)$ & $163(38.7)$ & 0.137 \\
\hline Hyperkalemia/hypokalemia & $10(2.2)$ & $15(3.6)$ & 0.245 \\
\hline Cardiac tamponade & $4(0.9)$ & $5(1.2)$ & 0.673 \\
\hline Tension pneumothorax & 0 & 0 & 1.000 \\
\hline Pulmonary thromboembolism & $13(2.9)$ & $15(3.6)$ & 0.590 \\
\hline Acute myocardial infarction & $34(7.6)$ & $29(6.9)$ & 0.677 \\
\hline Other cardiogenic & $91(20.4)$ & 79 (18.8) & 0.544 \\
\hline Anaphylaxis & $1(0.2)$ & $4(1.0)$ & 0.158 \\
\hline Neurologic & $28(6.3)$ & $18(4.3)$ & 0.189 \\
\hline Unknown & $34(7.6)$ & $28(6.7)$ & 0.579 \\
\hline
\end{tabular}

Values are presented as number (\%). Pre-implementation: February 2016 to January 2018, Post-implementation: February 2018 to January 2020. CPR: cardiopulmonary resuscitation; ICU: intensive care unit; DNR: do-not-resuscitation; POLST: physician orders of life sustaining treatment.

${ }^{a}$ CPR performed in terminally ill patients with no completed DNR or POLST documentation although there were discussions.

POLST documentation, and most of the POLST documentation was written with DNR after the initial cardiac arrest. In terms of whether the patient's will was reflected, the majority of POLST documentation (96.8\%) was completed by the patient's family members as surrogates because they did not know the patient's will or the patients did not express or decide their will regarding LST. The execution rate of withdrawal or withholding LSTs was $98.9 \%$ for CPR, $53.7 \%$ for hemodialysis, and $48.4 \%$ for mechanical ventilation in the POLST documents of CPR patients (Supplementary Table 3). Statistical difference was not observed in the number of DNR documents per month in total hospitalized patients (Figure 1). The characteristics of written DNR and POLST for hospitalized patients throughout the study period are described in Supplementary Table 4.

\section{DISCUSSION}

In the present study, the effect of introduction of the LST Decisions Act on the incidence of CPR, a main component of LST, was evaluated. The incidence of CPR and other related outcomes, such as CPR duration and 24-hour survival rate, did not differ before and after implementation of the Act. The enforcement of the LST Decisions Act legitimately allows withholding and withdrawal of LST. POLST, based on the Act, helps to ensure that patients receive care consistent with their preferences. CPR, including external cardiac massage, is an aggressive LST and might be physically harmful in patients at the EOL [4]. Therefore, when withholding or withdrawing LST is discussed with patients or caregivers and physicians, the decision whether to perform CPR is often the first and most frequently made decision $[14,15]$. The effect of the implementation of the LST Decisions Act and subsequent advance care 
Table 3. Primary and secondary study outcomes

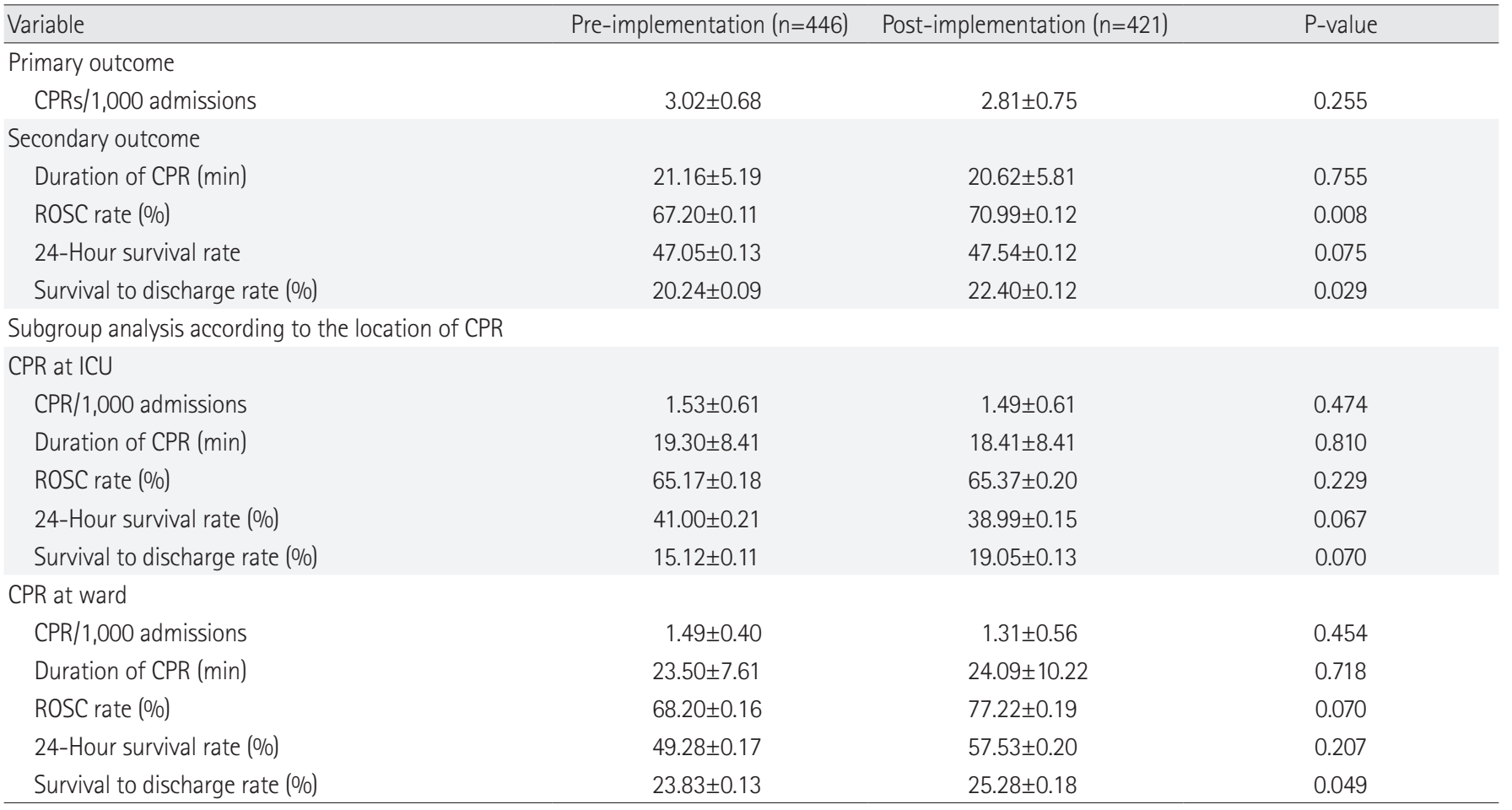

Values are presented as mean \pm standard deviation. Pre-implementation: February 2016 to January 2018, Post-implementation: February 2018 to January 2020. CPR: cardiopulmonary resuscitation; ROSC: return of spontaneous circulation; ICU: intensive care unit.

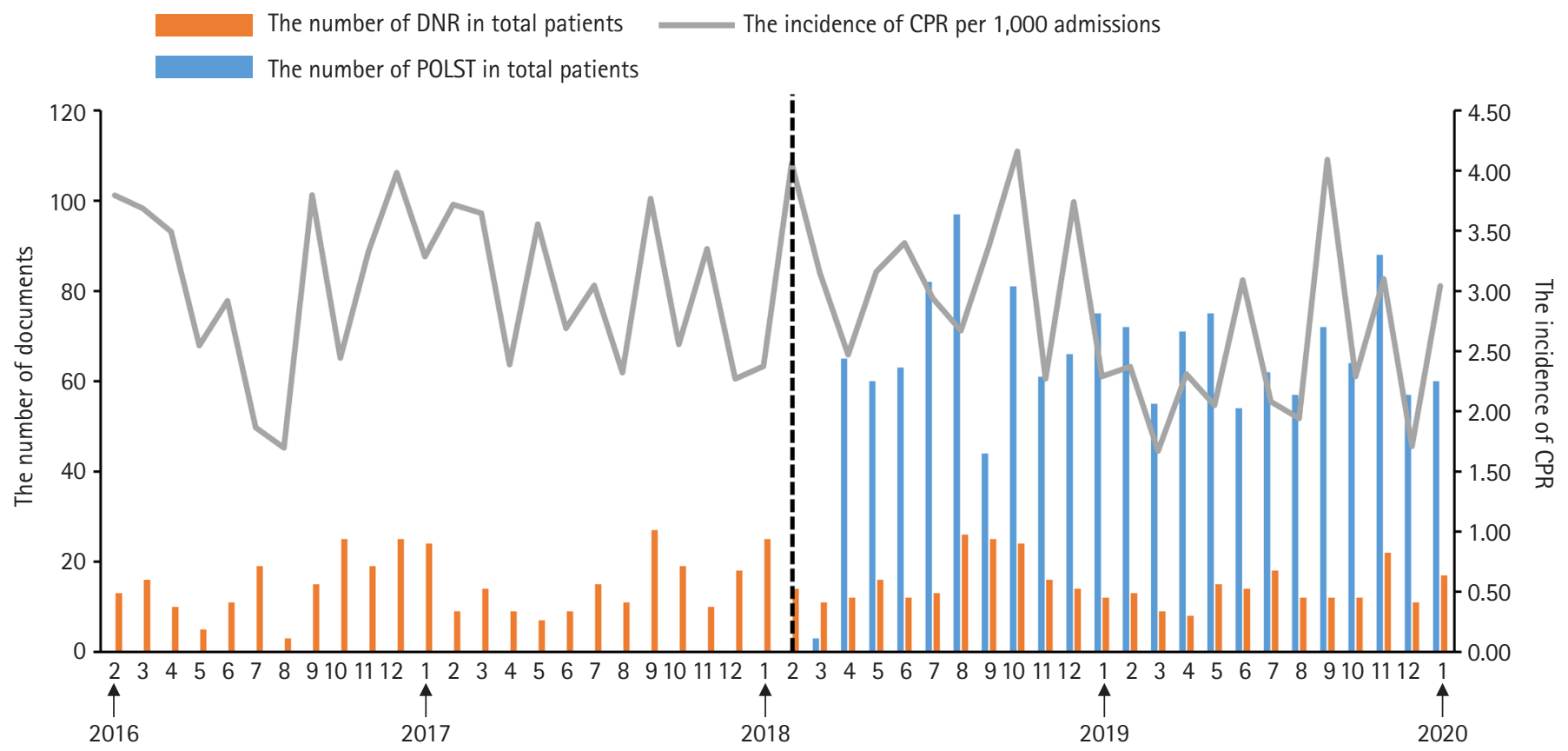

Figure 1. Monthly trends of do-not-resuscitate (DNR) and physician orders for life-sustaining treatment (POLST) documentation and the incidence of cardiopulmonary resuscitation (CPR) per 1,000 admissions. Pre-implementation: February 2016 to January 2018, Post-implementation: February 2018 to January 2020. The orange bars represent the number of DNR orders per month among hospitalized patients (Pre-implementation period, $14.92 \pm 6.87$ vs. Post-implementation period, $14.92 \pm 4.88 ; \mathrm{P}=1.000$ ). The blue bars represent the number of POLST documents per month among hospitalized patients $(61.83 \pm 22.00)$. The gray lines represent the incidence of CPR per 1,000 admissions per month among hospitalized patients $(2.92 \pm 0.71)$. 
Table 4. The characteristics of written DNR, POLST in CPR patients

\begin{tabular}{|c|c|c|c|}
\hline Variable & Pre-implementation $(n=446)$ & Post-implementation $(n=421)$ & P-value \\
\hline Total number of documentations & $240(53.8)$ & $143(34.0)$ & $<0.001$ \\
\hline DNR document & $240(53.8)$ & $48(11.4)$ & $<0.001$ \\
\hline Timing of writing DNR & & & 0.173 \\
\hline Before initial cardiac arrest & $6^{a}(2.5)$ & $3^{\mathrm{a}}(6.3)$ & \\
\hline After initial cardiac arrest & $234(97.5)$ & 45 (93.8) & \\
\hline Place where DNR was written & & & 0.007 \\
\hline $\mathrm{ICU}$ & $177(73.8)$ & $44(91.7)$ & \\
\hline General ward & $63(26.3)$ & $4(8.3)$ & \\
\hline DNR in medical or surgical patients & & & 0.472 \\
\hline Medical & $200(83.3)$ & $42(87.5)$ & \\
\hline Surgical & 40 (16.7) & $6(12.5)$ & \\
\hline POLST document & NA & $95(22.6)$ & \\
\hline \multicolumn{4}{|l|}{ Whether patient's will was reflected ${ }^{b}$} \\
\hline Yes & NA & $3^{c}(3.2)$ & \\
\hline No & NA & 92 (96.8) & \\
\hline \multicolumn{4}{|l|}{ Timing of writing POLST } \\
\hline Before initial cardiac arrest & NA & $2^{\mathrm{a}}(2.1)$ & \\
\hline After initial cardiac arrest & NA & 93 (97.9) & \\
\hline \multicolumn{4}{|l|}{ Place where POLST was written } \\
\hline ICU & NA & 85 (89.5) & \\
\hline General ward & NA & $10(10.5)$ & \\
\hline \multicolumn{4}{|l|}{ POLST in medical or surgical patients } \\
\hline Medical & NA & 80 (84.2) & \\
\hline Surgical & NA & 15 (15.8) & \\
\hline
\end{tabular}

Values are presented as number (\%). Pre-implementation: February 2016 to January 2018, Post-implementation: February 2018 to January 2020.

DNR: do-not-resuscitation; POLST: physician orders of life sustaining treatment; CPR: cardiopulmonary resuscitation; ICU: intensive care unit.

a In a total of $11 \mathrm{CPR}$ patients with documentation before initial cardiac arrest, eight patients or surrogates canceled the documentation and three patients underwent CPR regardless of intact documentation; 'If form 1(when the patient's own decision-making competency was preserved) or form 10 (when an advance directive was already written by the patient) were filled out, we judged that the patient's own will was reflected in the POLST documentation; 'POLST documentation in all of three patients were completed after the occurrence of initial cardiac arrest. In one patient, an advance directive was prepared beforehand, but CPR was performed due to sudden cardiac arrest. Two patients themselves completed POLST documentation after return of spontaneous circulation.

planning and directives have been previously studied $[16,17]$. However, the changes in the overall incidence of CPR and after implementation of the LST Decisions Act have not been reported. Therefore, whether the implementation of the LST Decisions Act and application of standardized documentation regarding advance directives and care planning actually affects the incidence of CPR in the present study in terms of its original purpose was investigated in the present study.

CPR included in the present study had several similarities and differences compared with previous studies. The causes of cardiac arrest in the present study were consistent with a previous report showing predominant detectable causes of in-hospital cardiac arrest to be cardiac causes and hypoxia [18]. In contrast, the proportion of cardiac arrests with myocardial infarction was relatively low compared with results reported in two observational studies $[19,20]$. The proportion of unpreventable CPR was comparable with or slightly higher than that in previous studies [21,22]. The ROSC rate and 24-hour survival rate were similar to or higher than those reported in other studies $[19,20]$, but the total survival-to-discharge rate was lower $[19,20]$. In subgroup analysis, the survival outcomes of CPR were poor for patients in the ICU setting, consistent with a previous study [23]. The unadjusted results in the present study are likely because patients in the ICU often experience organ failure in addition to serious preexisting comorbidities [24]. The ROSC rate and survival-to-discharge rate showed a moderate increase after implementation of the LST Decisions Act and appear mainly associated with improved outcomes of CPR in the ward based on subgroup analysis. Because various factors affecting the clinical outcomes of CPR were not 
excluded and outcome indices mainly improved in CPR in the ward, external factors such as improved CPR quality or a rapid response team might be involved [25].

In the present study, significant difference was not observed in the incidence of CPR before and after implementation of the LST Decisions Act. We hypothesized the implementation of the LST Decisions Act and the subsequent proactive preparation for POLST reduce unnecessary CPR in terminally ill patients. To confirm the incidence of CPR based on this hypothesis, a significant portion of CPRs in the pre-implementation period must be attributed to delayed LST documentation in patients at EOL [26]. In the present study, only $7 \%$ of the CPRs in hospitalized patients during the pre-implementation period were associated with delayed DNR documentation, likely indicating the majority of CPRs during the study period occurred irrespective of the presence of terminal illness or EOL. Thus, the incidence of CPR might not decrease regardless of the proportion of completed documentation before initial cardiac arrest. Second, the unestablished practice of proactive preparation of POLST might have contributed to the results. In this study, the proportion of CPRs due to delayed documentation remained the same without any significant difference, even after implementation of the LST Decisions Act. Although a system that withheld or withdrew the LST was introduced, LST including CPR for terminally ill patients continued if the proactive preparation for POLST was not widespread. In summary, CPR that occurred in terminally ill patients with DNR or POLST documentation accounted for only a minor portion, and implementation of the LST Decisions Act did not reduce the frequency of CPR due to delayed documentation in those patients, which could have contributed to the current results.

There were several notable points after implementation of the LST Decisions Act. First, the proportion of DNR documentation significantly decreased. Because DNR documentation was mostly written after initial cardiac arrest during both periods in CPR patients, the changes in the proportion of DNR documentation unlikely affected the incidence of CPR. This might be because the LST Decisions Act provided a new approach, the POLST, to withhold or withdraw LST including reCPR in terminally ill patients who underwent CPR. Second, the proportion of completed DNR or POLST documentation in CPR patients decreased. Because most DNR or POLST documentation was completed immediately before death in CPR patients after initial cardiac arrest, the lower proportion of completed DNR or POLST in CPR patients can be explained partially by the significantly better outcomes of CPR in the post-implementation period. Thus, because the proportion of recovery was higher in the post-implementation period, the number of completed DNR or POLST documentation in CPR patients without probability of recovery was assumedly lower in the post-implementation period. Lastly, the ratio of DNR or POLST documents and death among hospitalized patients was much higher in the post-implementation period, indicating the proportion of withholding or withdrawal of LST based on documentation significantly increased. However, as the self-determination rate was low and the interval between completion of DNR or POLST and death was short compared with Western countries [27-29], many additional procedures are needed to broadly establish the LST Decisions Act.

The change in the incidence of CPR, the main component of LST, was analyzed for the first time before and after implementation of LST decisions and is the main strength of the present study. However, the present study had several limitations that should be considered before interpreting the results. First, due to the retrospective design, the results might be subjected to biases and limitations of retrospective studies. Estimating the effectiveness of the LST Decisions Act and related POLST forms to protect patients from unwanted LST is difficult. The present study did not include information regarding the exact timing when discussion of POLST and each component of LST other than CPR were started, which might have helped better explain the results. In addition, confounding factors that could affect the incidence of CPR and CPR-related outcomes were not excluded. However, patient groups in the two periods were comparable because the age, sex, CMI, and Charlson comorbidity index scores were not significantly different. Furthermore, because most patients and their surrogates agreed that CPR should not be performed when implementing the POLST, the effect of LST components other than CPR on the incidence of CPR was limited. Second, data on all terminally ill patients who were hospitalized in our hospital during the study period were not included in the analysis and only the proportion of terminally ill patients among CPR patients was estimated indirectly. Finally, generalizing the study results is difficult because decisions on LST are mainly influenced by country and sociocultural differences.

In conclusion, the incidence of CPR before and after implementation of the LST Decisions Act basically remained the same. Further studies are needed to determine how LST decisions affect whether CPR and other LSTs are performed in real practice. 


\section{CONFLICT OF INTEREST}

No potential conflict of interest relevant to this article was reported.

\section{ACKNOWLEDGMENTS}

The authors thank Wonho Choi in the Center for Palliative Care and Clinical Ethics of Seoul National University Hospital for providing summarized data and detailed information regarding the physician orders for life-sustaining treatment forms.

\section{ORCID}

Hyunjae Im Hyun Woo Choe https://orcid.org/0000-0002-8158-3820

Seung-Young Oh https://orcid.org/0000-0003-0874-5835

Ho Geol Ryu https://orcid.org/0000-0001-8281-2851 https://orcid.org/0000-0001-8952-6049

Hannah Lee https://orcid.org/0000-0002-4001-1826

\section{AUTHOR CONTRIBUTIONS}

Conceptualization: HI, HL. Data curation: HI, HWC, HL. Formal analysis: HI, SYO, HL. Methodology: HI, HL, HGR, SYO. Project administration: HI, HWC, HL. Visualization: HI. Writing-original draft: HI. Writing-review \& editing: HI, HL, HGR.

\section{SUPPLEMENTARY MATERIALS}

Supplementary materials can be found via https://doi.org/ 10.4266/acc.2021.01095.

\section{REFERENCES}

1. Decisions near the end of life. Council on Ethical and Judicial Affairs, American Medical Association. JAMA 1992;267:222933.

2. Reynolds S, Cooper AB, McKneally M. Withdrawing life-sustaining treatment: ethical considerations. Thorac Surg Clin 2005;15:469-80.

3. Krischer JP, Fine EG, Davis JH, Nagel EL. Complications of cardiac resuscitation. Chest 1987;92:287-91.

4. Deliliga A, Chatzinikolaou F, Koutsoukis D, Chrysovergis I, Voultsos P. Cardiopulmonary resuscitation (CPR) complications encountered in forensic autopsy cases. BMC Emerg Med
2019;19:23.

5. Compton S, Grace H, Madgy A, Swor RA. Post-traumatic stress disorder symptomology associated with witnessing unsuccessful out-of-hospital cardiopulmonary resuscitation. Acad Emerg Med 2009;16:226-9.

6. Kim H, Im HS, Lee KO, Min YJ, Jo JC, Choi Y, et al. Changes in decision-making process for life-sustaining treatment in patients with advanced cancer after the life-sustaining treatment decisions-making act. BMC Palliat Care 2021;20:63.

7. Kim JS, Yoo SH, Choi W, Kim Y, Hong J, Kim MS, et al. Implication of the life-sustaining treatment decisions act on endof-life care for Korean terminal patients. Cancer Res Treat 2020;52:917-24

8. Brinkman-Stoppelenburg A, Rietjens JA, van der Heide A. The effects of advance care planning on end-of-life care: a systematic review. Palliat Med 2014;28:1000-25.

9. Han B, Chen X, Li Q. Application of case mix index in the allocation of nursing human resources. J Nurs Manag 2018;26:64752.

10. Part 6: advance cardiovascular life support. Section 7: algorithm approach to ACLS emergencies. 7A: principles and practice of ACLS. European Resuscitation Council. Resuscitation 2000;46:163-6.

11. Jacobs I, Nadkarni V, Bahr J, Berg RA, Billi JE, Bossaert L, et al. Cardiac arrest and cardiopulmonary resuscitation outcome reports: update and simplification of the Utstein templates for resuscitation registries: a statement for healthcare professionals from a task force of the International Liaison Committee on Resuscitation (American Heart Association, European Resuscitation Council, Australian Resuscitation Council, New Zealand Resuscitation Council, Heart and Stroke Foundation of Canada, InterAmerican Heart Foundation, Resuscitation Councils of Southern Africa). Circulation 2004;110:3385-97.

12. Wagner AK, Soumerai SB, Zhang F, Ross-Degnan D. Segmented regression analysis of interrupted time series studies in medication use research. J Clin Pharm Ther 2002;27:299-309.

13. Bhargava A, Franzini L, Narendranathan W. Serial correlation and the fixed effects model. Rev Econ Stud 1982;49:533-49.

14. Kirchhoff KT, Anumandla PR, Foth KT, Lues SN, Gilbertson-White SH. Documentation on withdrawal of life support in adult patients in the intensive care unit. Am J Crit Care 2004;13:328-34

15. Lee SI, Hong KS, Park J, Lee YJ. Decision-making regarding withdrawal of life-sustaining treatment and the role of intensivists in the intensive care unit: a single-center study. Acute Crit Care 2020;35:179-88. 
16. Beach MC, Morrison RS. The effect of do-not-resuscitate orders on physician decision-making. J Am Geriatr Soc 2002;50:205761.

17. Vranas KC, Lin AL, Zive D, Tolle SW, Halpern SD, Slatore CG, et al. The association of physician orders for life-sustaining treatment with intensity of treatment among patients presenting to the emergency department. Ann Emerg Med 2020;75:171-80.

18. Andersen LW, Holmberg MJ, Berg KM, Donnino MW, Granfeldt A. In-hospital cardiac arrest: a review. JAMA 2019;321:1200-10.

19. Tirkkonen J, Hellevuo H, Olkkola KT, Hoppu S. Aetiology of in-hospital cardiac arrest on general wards. Resuscitation 2016;107:19-24.

20. Bergum D, Nordseth T, Mjølstad OC, Skogvoll E, Haugen BO. Causes of in-hospital cardiac arrest: incidences and rate of recognition. Resuscitation 2015;87:63-8.

21. Yang E, Lee H, Lee SM, Kim S, Ryu HG, Lee HJ, et al. Effectiveness of a daytime rapid response system in hospitalized surgical ward patients. Acute Crit Care 2020;35:77-86.

22. Cho JY, Lee DS, Choi YY, Park JS, Cho YJ, Yoon HI, et al. Analysis of avoidable cardiopulmonary resuscitation incidents with a part-time rapid response system in place. Acute Crit Care 2021;36:109-17.

23. Perman SM, Stanton E, Soar J, Berg RA, Donnino MW, Mikkelsen ME, et al. Location of in-hospital cardiac arrest in the
United States: variability in event rate and outcomes. J Am Heart Assoc 2016;5:e003638.

24. Leloup M, Briatte I, Langlois A, Cariou A, Lesieur O; ACIR study group. Unexpected cardiac arrests occurring inside the ICU: outcomes of a French prospective multicenter study. Intensive Care Med 2020;46:1005-15.

25. Girotra S, Nallamothu BK, Spertus JA, Li Y, Krumholz HM, Chan PS, et al. Trends in survival after in-hospital cardiac arrest. N Engl J Med 2012;367:1912-20.

26. Ouyang DJ, Lief L, Russell D, Xu J, Berlin DA, Gentzler E, et al. Timing is everything: early do-not- resuscitate orders in the intensive care unit and patient outcomes. PLoS One 2020;15:e0227971.

27. Zive DM, Fromme EK, Schmidt TA, Cook JN, Tolle SW. Timing of POLST form completion by cause of death. J Pain Symptom Manage 2015;50:650-8.

28. Levin TT, Li Y, Weiner JS, Lewis F, Bartell A, Piercy J, et al. How do-not-resuscitate orders are utilized in cancer patients: timing relative to death and communication-training implications. Palliat Support Care 2008;6:341-8.

29. van der Heide A, Deliens L, Faisst K, Nilstun T, Norup M, Paci E, et al. End-of-life decision-making in six European countries: descriptive study. Lancet 2003;362:345-50. 